BMJ Open Diabetes

Research \& Care

To cite: Sjöholm A. Atypical diabetes: a diagnostic challenge. BMJ Open Diab Res Care 2020;8:e001470. doi:10.1136/ bmjdrc-2020-001470

Received 21 April 2020 Revised 17 June 2020 Accepted 27 June 2020
Check for updates

(C) Author(s) (or their employer(s)) 2020. Re-use permitted under CC BY-NC. No commercial re-use. See rights and permissions. Published by BMJ.

Department of Internal Medicine, Region Gävleborg, Gavle, Sweden

Correspondence to Dr. Åke Sjöholm; ake.sjoholm@regiongavleborg. se

\title{
Atypical diabetes: a diagnostic challenge
}

\author{
Åke Sjöholm
}

\begin{abstract}
In medical school, we learned how to classify diabetes according to different clinical characteristics. However, at the dawn of the precision medicine era, it is clear that today's clinical reality does not always align well with textbook teachings. The terms juvenile versus elderlyonset diabetes, as well as insulin-dependent versus non-insulin-dependent diabetes, have become obsolete. Contrary to what is often taught severe ketoacidosis may occur in type 2 diabetes. Patients may also suffer from two or more forms of diabetes simultaneously or consecutively. Five authentic cases of diabetes with uncommon characteristics that pose diagnostic challenges are presented here.
\end{abstract}

\section{INTRODUCTION}

During clinical training in medical school, many of us have been taught how to classify diabetes according to different clinical characteristics into two main groups, type 1 diabetes (T1D) or type 2 diabetes (T2D), and some unusual types (see below).

T1D is believed to be due to an autoimmune attack of antibodies, inter alia, against the $\beta$-cell antigen GAD-65, with the subsequent functional suppression and eventual destruction of the insulin-producing $\beta$-cells. T1D was previously called juvenile diabetes based on the incidence of the disease being highest at these ages. ${ }^{1}$ However, T1D can unfold at any age and there is also a variant of T1D, 'latent autoimmune diabetes in adults', a relatively slow-progressing autoimmune destruction of $\beta$-cells in slightly older individuals. ${ }^{2}$

T2D is more of a cardiovascular lifestyle disease in which physical inactivity and excess caloric intake result in visceral obesity with accompanying insulin resistance, which in genetically predisposed individuals results in manifest diabetes. ${ }^{3}$ T2D was previously called elderly-onset diabetes because the prevalence increases with increasing age. As we will see below, this designation is now completely misleading. In the past T2D has also been called non-insulin-dependent diabetes, an epithet that is also inappropriate as at least $30 \%$ of patients with T2D sooner or later need supplemental therapy with insulin in some form due to a progressive loss of $\beta$-cells. ${ }^{4}$
It is also now clear that there are at least four distinct phenotypes of ketosis-prone diabetes ${ }^{56}: \mathrm{A}^{-} \mathrm{B}^{-}$, autoantibody negative and with absent $\beta$-cells; $\mathrm{A}^{+} \mathrm{B}^{-}$, autoantibody positive and with absent $\beta$-cells (autoimmune T1D); $\mathrm{A}^{-} \mathrm{B}^{+}$, autoantibody negative and with present $\beta$-cells; $A^{+} B^{+}$, autoantibody positive and with present $\beta$-cells.

Both T1D and T2D are polygenic diseases where both environmental factors and heredity (especially in T2D) play a role, but the exact genetic defects and their inheritance and penetrance remain elusive. Recent studies have shown that both T1D and T2D are significantly more complex and heterogeneous diseases than previously appreciated. $^{137}$

In addition to these groups are, inter alia, different types of monogenic diabetes, for example, various forms of 'maturity-onset diabetes in the youth' (MODY) ${ }^{8-11}$ MODY accounts for only $2 \%-3 \%$ of all diabetes in the western world, although there is reason to believe this to be a strong underestimation. In MODY, the genetic defects (usually heterozygous) are known and inherited autosomally dominant, which means that a child of a patient with MODY in principle is at $50 \%$ risk of contracting the disease himself or herself (the actual risk depends on the penetration of the mutation). It is also possible that patients may suffer from (at least) two different types of diabetes simultaneously or consecutively. ${ }^{9}$

Being a clinician researcher with translational research background, seeing patients with diabetes on a daily basis for the past 30 years, the heterogeneity of diabetes has become more and more evident for every year in the clinic. Along with great strides in precision medicine diagnostics, and the emergence of novel drugs with proven effects on diabetes-related mortality and morbidity, this makes it very exciting times to be a diabetologist.

All below participants gave written informed consent to this paper. Because this paper is not reporting scientific research, but merely routine diabetes care, approval by an ethics committee was considered not to be required. 


\section{CASE DESCRIPTIONS}

\section{Patient 1}

The patient is previously essentially healthy in the 40 s with newly diagnosed diabetes, which led to a referral to the emergency room. The patient had for 2 weeks classic catabolic symptoms of polyuria, polydipsia, severe weight loss and vomiting. In the emergency room, the patient was cold, hypotensive and strikingly tachypneic. The P-glucose was $68 \mathrm{mmol} / \mathrm{L}$ and P-C-peptide $0.337 \mathrm{nmol} / \mathrm{L}$. Arterial blood gas analysis showed a $\mathrm{pH}$ of 7.03 , base excess (BE) $-25 \mathrm{mmol} / \mathrm{L}$ and B-ketones $7.4 \mathrm{mmol} / \mathrm{L}$, thus a severe diabetic ketoacidosis. The patient was transferred to the intensive care unit with intravenous insulin and fluid, later put on basal bolus insulin subcutaneously and discharged with insulin glargine $72 \mathrm{U}$ once a day+insulin lispro $18 \mathrm{U}$ three times a day with a diagnosis of T1D with ketoacidosis.

When revisiting the outpatient clinic 6 weeks later, the patient had a body mass index (BMI) of $35.5 \mathrm{~kg} / \mathrm{m}^{2}$ and an $\mathrm{HbAlc}$ of $91 \mathrm{mmol} / \mathrm{mol}$. There were several cases of T2D on both sides in the family. The patient was negative for autoantibodies against GAD-65 and IA-2 and now showed a robust insulin production with a basal level of C-peptide of $1.78 \mathrm{nmol} / \mathrm{L}$ that rose postprandially to 2.45 $\mathrm{nmol} / \mathrm{L}$ (ie, $\mathrm{A}^{-} \mathrm{B}^{+}$ketotic diabetes according to the $\mathrm{AB}$ classification scheme $\mathrm{E}^{5610}$ ). The diagnosis was changed to T2D. The target level for HbA1c was set to $<42 \mathrm{mmol} /$ mol and the patient received treatment with dulaglutide $1.5 \mathrm{mg}$ once a week and the combination tablet Synjardy (empagliflozin $5 \mathrm{mg}+$ metformin $850 \mathrm{mg}$ ) two times per day. Ten weeks later, the patient was referred back to primary care with an HbA1c of $36 \mathrm{mmol} / \mathrm{mol}$ and a $\mathrm{fP}$-glucose $\sim 5 \mathrm{mmol} / \mathrm{L}$. Ten months later, HbAlc remained at $36 \mathrm{mmol} / \mathrm{mol}$, the patient felt excellent, had discontinued almost all insulin and had lost $26 \mathrm{~kg}$ of weight during this time.

This case illustrates that the dogma that patients with T2D do not develop ketoacidosis is a myth. That this patient developed severe ketoacidosis may have been caused by a temporary inhibition of insulin secretion (low C-peptide of $0.337 \mathrm{nmol} / \mathrm{L}$ ) due to severe hyperglycemia (P-glucose $68 \mathrm{mmol} / \mathrm{L}$ ), so-called glucose toxicity, to which the $\beta$-cell is very sensitive. ${ }^{12}$ Insulin production recovers, as in this case, after insulin treatment.

The $\mathrm{AB}$ classification has permitted etiological definitions following longitudinal ascertainment of the stability of the different subtypes. ${ }^{5} 613$ Novel etiologies have been uncovered for the ketosis proneness of patients with unprovoked $\mathrm{A}^{-} \mathrm{B}^{+}$ketotic diabetes $(\mathrm{eg}$, such as this patient), including hypercatabolism of leucine/isoleucine $^{14}$ and defective intracellular availability of arginine. ${ }^{15}$ In the broader context of $\mathrm{A}^{-} \mathrm{B}^{+}$ketotic diabetes, 'occult' islet autoimmunity (in the shape of T cell-mediated $\beta$-cell dysfunction) also can occur. ${ }^{16}$

For long-term treatment, there are now far more attractive alternatives than insulin to achieve a powerful antidiabetic effect in T2D without the risk of hypoglycemia and with weight loss instead of weight gain.

\section{Patient 2}

A patient in the upper teens was transferred from the Department of Pediatrics, having been diagnosed with non-ketotic T2D at just 13 years of age. The patient's father was diagnosed with T2D at age 48 and the patient had a BMI of $35.2 \mathrm{~kg} / \mathrm{m}^{2}$ and an HbAlc of $77 \mathrm{mmol} /$ mol. The patient was treated with insulin degludec 31 $\mathrm{U}$ once a day, mealtime insulin lispro 10-12 U three times a day and metformin $500 \mathrm{mg}$ three times a day but reported significant hypoglycemia problems. The patient was negative for autoantibodies against GAD-65 and IA-2 and had a very good insulin production with a basal level of C-peptide of $1.32 \mathrm{nmol} / \mathrm{L}$ that after meal stimulation rose to $1.87 \mathrm{nmol} / \mathrm{L}$.

All insulin and metformin were stopped and replaced with dulaglutide $0.75 \mathrm{mg}$ once a week and the combination tablet Synjardy (empagliflozin 5 mg+metformin 850 $\mathrm{mg}$ ) two times per day. The target level for HbAlc was set to $<42 \mathrm{mmol} / \mathrm{mol}$. Molecular genetic analysis found no evidence for monogenic diabetes (MODY 1-3). Three months later, the patient had lost $10 \mathrm{~kg}$ in weight, had an $\mathrm{HbAlc}$ of $40 \mathrm{mmol} / \mathrm{mol}$ and was insulin free.

The lesson to be learnt from this case is that T2D is by no means just a disease of the elderly. Although T2D in children is still uncommon in Northern Europe, it is likely that an increase will be seen subsequent to the relentless rise in BMI in this population. In the USA, up to $45 \%$ of all newly diagnosed diabetes in children $(<18$ years) is T2D, ${ }^{17}$ especially in African-American and Latin American groups. ${ }^{18}$

Recent reports have shown alarmingly rapid $\beta$-cell dysfunction and chronic angiopathic complications among patients with childhood-onset T2D,${ }^{19-21}$ calling for aggressive and multifactorial treatment of these patients.

\section{Patient 3}

A patient in the upper teens was referred to us because of diabetes, classified as T2D, debuting at the age of 16 . The patient underwent unilateral nephrectomy at 6 months of age due to cystic kidney disease.

Analyses of autoantibodies against GAD-65, IA-2, ICA, ZnT8 and insulin itself were negative. The patient had a decent insulin production with a basal level of C-peptide of $0.52 \mathrm{nmol} / \mathrm{L}$ that after a meal rose to $0.98 \mathrm{nmol} / \mathrm{L}$. The patient was on a basal bolus insulin regimen, BMI was $28.9 \mathrm{~kg} / \mathrm{m}^{2}$ and HbAlc $52 \mathrm{mmol} / \mathrm{mol}$.

The history of neonatal nephrectomy due to cystic kidney disease, together with the patient's atypical diabetes, brought MODY-5 to mind. Patients with MODY-5, which is due to mutations in the transcription factor hepatocyte nuclear factor $1 \beta$, oftentimes have renal cysts. MODY-5 is therefore also called renal cysts and diabetes syndrome. ${ }^{10}{ }^{11}$ Malformations in other urogenital organs and pancreatic atrophy are sometimes also seen. Radiological evaluation confirmed that the 
patient's pancreas is small and that several cortical cysts are present in the remaining kidney. In MODY-5, it is advisable that diabetologists and nephrologists collaborate closely, as these patients have a high risk of developing end-stage renal failure before the age of $45 .^{11}$ Examination of the histology of the patient's removed kidney showed multicystic renal dysplasia with a mixture of primitive glomeruli, cysts and primitive tissue (bone and cartilage).

Contrary to widespread belief, heredity is not mandatory in MODY; new data show that about $50 \%$ of cases have spontaneous (de novo) mutations and in some cases the patient in fact has a different father than he/ she believed.

Consultations were made with the University of Exeter, world leaders in the field and very helpful and accommodating also with advice (https://www.diabetesgenes. org). There is also a free and useful risk calculator on their website, https://www.diabetesgenes.org/modyprobability-calculator, which showed $75 \%$ MODY risk for the patient. The Exeter laboratory analyzed all 50 today known causes for monogenic diabetes with 'next generation sequencing' methodology, but with a negative outcome. However, this does not necessarily exclude MODY but merely means that, with today's sequencing methodology, detectable changes in MODY genes known to date could not be detected. For example, non-coding mutations and epigenetic lesions escape detection. Patients with 'Typical' MODY, but with negative diagnostics, are usually referred to as MODY-X. By analyzing 'type 1 diabetes genetic risk score', the Exeter laboratory could exclude T1D in this patient.

In view of the patient being found to have a nonautoimmune, non-insulinopenic diabetes, an attempt was made to replace the insulin treatment with Glyxambi (empagliflozin $10 \mathrm{mg}$ +linagliptin $5 \mathrm{mg}$ ) once a day, which, however, produced a very weak effect and was discontinued after 2 weeks. Instead, semaglutide once a week was used in escalation doses together with the combination tablet Synjardy (empagliflozin $5 \mathrm{mg}+$ metformin $850 \mathrm{mg}$ ) two times per day. Due to severe nausea and vomiting, semaglutide was replaced with the previous insulin regimen with good effect.

The patient's diabetes is considered not as atypical T2D, but as MODY-X (Professor A T Hattersley, personal communication).

The lesson of this case is again that not all teenagers can a priori be presumed to have T1D and that one should keep MODY in mind if the patient is autoantibody negative and has a well-preserved insulin production.

\section{Patient 4}

A patient in the mid-20s was referred from a university hospital for diabetes care. The patient had surgery for craniopharyngioma in 2001 with postoperative radiation and shunt insertion. The patient then developed a number of pituitary hormonal deficiencies that are substituted. In 2009, at the age of 16, the patient was diagnosed with diabetes. The patient's mother was diagnosed with T2D at the age of 30 .

The patient had a BMI of $29.4 \mathrm{~kg} / \mathrm{m}^{2}$ and an HbAlc of $81 \mathrm{mmol} / \mathrm{mol}$ and was treated with Neutral Protamine Hagedorn $(\mathrm{NPH})$ insulin $60 \mathrm{U}$ once a day (since 4 months), metformin $500 \mathrm{mg} \mathrm{1+1+2}$ and liraglutide 1.8 $\mathrm{mg}$ once a day and substitution doses of hydrocortisone, levothyroxine, somatropin, desmopressin, prasterone and ethinylestradiol/levonorgestrel. The patient had previously tried various SGLT2 inhibitors but reacted with pronounced genital fungal infections. The patient was negative for autoantibodies against GAD-65 and IA-2 and had a basal level of C-peptide of an astonishing 10 $\mathrm{nmol} / \mathrm{L}$, indicating an extremely potent insulin production secondary to a severe insulin resistance. Interestingly, the patient's doctor at the 2009 diabetic diagnosis had noted a brownish hyperpigmentation of the neck-acanthosis nigricans?

The patient was started on the PPAR- $\gamma$ agonist pioglitazone $15 \mathrm{mg}$ in the form of the combination tablet Competact (containing also $850 \mathrm{mg}$ metformin) two times per day. The target level for HbAlc was set to $<42$ $\mathrm{mmol} / \mathrm{mol}$. Two months later, the HbAlc had decreased to $51 \mathrm{mmol} / \mathrm{mol}$ and because of frequent hypoglycemia, all insulin was discontinued and instead Competact was increased to three times a day, resulting in an HbAlc of $37 \mathrm{mmol} / \mathrm{mol}$ some months later.

Analysis of monogenic diabetes in Exeter, focusing on genes involved in insulin resistance, for example, INSR, PPARG or DYRK1B (https://www.diabetesgenes. org/tests-for-diabetes-subtypes / a-new-test-for-all-modygenes/), was negative.

The lesson of this case is to consider the possibility of secondary diabetes, even in young individuals, and that in cases of severe insulin resistance the PPAR- $\gamma$ agonist pioglitazone-which has been overshadowed by GLP-1-based therapy and SGLT2 inhibitors-may be very effective.

\section{Patient 5}

The patient in the 30s was diagnosed with T1D at age 10 and was treated with insulin for 10 years. Because of massive heredity for diabetes and very low insulin requirements, MODY was suspected. The patient, as well as one of the sisters, proved to be heterozygous for a mutation in the enzyme glucokinase (GCK: C.1305-1306INSG) and was accordingly diagnosed with MODY-2.

MODY-2 is due to inactivating mutations in GCK, which is expressed in, for example, the insulin-producing $\beta$-cells and in the liver. ${ }^{11}$ GCK is a critical component of $\beta$-cell glucose sensing and heterozygous defects in this enzyme result in mild fasting hyperglycemia that can be asymptomatic for many years and is often detected by coincidence.

As expected, the patient's glycemic control was excellent on only dietary treatment for 10 years, but the patient then sought the emergency room because of 3 months of polyuria, polydipsia, fatigue and $20 \mathrm{~kg}$ weight loss. P-glucose was $29 \mathrm{mmol} / \mathrm{L}$ and $\mathrm{HbAlc} 117 \mathrm{mmol} / \mathrm{mol}$. Arterial blood gas and electrolytes were normal and B-ketones 0.2 
$\mathrm{mmol} / \mathrm{L}$. The patient was admitted to the hospital with a basal bolus insulin regimen and fluid replacement. Analysis of autoantibodies against GAD-65 showed $314 \mathrm{E} / \mathrm{mL}$ $($ ref $<5)$ and against IA-2 was $513 \mathrm{E} / \mathrm{mL}($ ref $<7.5)$, thus a strong autoimmune process. The patient's insulin production was weak, as evidenced by a level of $\mathrm{C}$-peptide that only increased from 0.26 to $0.42 \mathrm{nmol} / \mathrm{L}$ on meal stimulation. The patient was found to be very sensitive to insulin, perhaps not so unexpectedly, as GCK is also expressed in glucagon-producing $\alpha$-cells in the pancreas and in glucosesensitive neurons in the central nervous system. ${ }^{22} 23$

Thus, this patient has been affected by two types of diabetes, a congenital monogenic form (MODY-2) and an acquired autoimmune form (T1D) directed against known $\beta$-cell antigens. This is an unexpected and surprising finding, as MODY-2 and autoimmune diabetes have nothing mechanistically in common in $\beta$-cell dysfunction. The mutation in GCK makes $\beta$-cell insulin secretion less sensitive to glucose while the autoimmune process results in apoptotic cell death, two fundamentally different mechanisms.

Coexistence of MODY and autoantibodies against known $\beta$-cell antigens is uncommon, but not unique, and a $1 \%$ figure has been reported. ${ }^{24}$ However, the overwhelming majority of these cases are not associated with the typical catabolic manifestations of T1D with pronounced hyperglycemia. According to data in the literature, only five cases of overt autoimmune diabetes in patients with MODY-2 have previously been published. ${ }^{24-27}$

The lesson of this case is that one diagnosis does not exclude another, something to remember not least in the case of an unexpected deterioration in glycemic control in a patient with previously stable diabetes.

\section{CONCLUSIONS}

This review illustrates the difficulties in properly diagnosing, and thus providing proper treatment for diabetes that does behave as in the school book. What sometimes is termed atypical diabetes may actually constitute uncommon forms of presentation and evolution of diabetes. T2D can occur in teenagers, usually with positive heredity and high BMI that may already be stigmatizing for a young person. To further risk increasing BMI with insulin, not infrequently in high doses, is hardly the right way to go in 2020 when excellent alternatives to achieve the opposite with simultaneous organ protection and without the risk of hypoglycemia are available. ${ }^{28}$ Atypical characteristics of young patients with non-insulinopenic diabetes should bring MODY to mind. One should also consider that patients may suffer from two or more forms of diabetes simultaneously or consecutively.

Considering the heterogeneity of diabetes that has become increasingly clear, the rapidly evolving powerful molecular genetic diagnostics, and the growing number of antidiabetic drugs proven to reduce macrovascular morbidity and mortality, make it very exciting times for the diabetes community.

Contributors ÅS cared for the patients, wrote and edited the manuscript.
Funding The authors have not declared a specific grant for this research from any funding agency in the public, commercial or not-for-profit sectors.

Competing interests ÅS has received lecture and consultancy fees from Boehringer Ingelheim, MSD, Sanofi, Pfizer and AstraZeneca.

Patient consent for publication Not required.

Provenance and peer review Not commissioned; externally peer reviewed.

Data availability statement Data are available upon reasonable request. Data are in each patient's medical record.

Open access This is an open access article distributed in accordance with the Creative Commons Attribution Non Commercial (CC BY-NC 4.0) license, which permits others to distribute, remix, adapt, build upon this work non-commercially, and license their derivative works on different terms, provided the original work is properly cited, appropriate credit is given, any changes made indicated, and the use is non-commercial. See: http://creativecommons.org/licenses/by-nc/4.0/.

ORCID iD

Åke Sjöholm http://orcid.org/0000-0002-5274-9748

\section{REFERENCES}

1 Ilonen J, Lempainen J, Veijola R. The heterogeneous pathogenesis of type 1 diabetes mellitus. Nat Rev Endocrinol 2019;15:635-50.

2 Grill V. LADA: a type of diabetes in its own right? Curr Diabetes Rev 2019;15:174-7.

3 Roden M, Shulman GI. The integrative biology of type 2 diabetes. Nature 2019;576:51-60.

4 Prospective Diabetes Study Group. U.K. prospective diabetes study 16. Overview of 6 years' therapy of type II diabetes: a progressive disease. U.K. prospective diabetes Study Group. Diabetes 1995;44:1249-58.

5 Maldonado M, Hampe CS, Gaur LK, et al. Ketosis-prone diabetes: dissection of a heterogeneous syndrome using an immunogenetic and beta-cell functional classification, prospective analysis, and clinical outcomes. J Clin Endocrinol Metab 2003;88:5090-8.

6 Balasubramanyam A, Nalini R, Hampe CS, et al. Syndromes of ketosis-prone diabetes mellitus. Endocr Rev 2008;29:292-302.

7 Dennis JM, Shields BM, Henley WE, et al. Disease progression and treatment response in data-driven subgroups of type 2 diabetes compared with models based on simple clinical features: an analysis using clinical trial data. Lancet Diabetes Endocrinol 2019;7:442-51.

8 Udler MS, McCarthy MI, Florez JC, et al. Genetic risk scores for diabetes diagnosis and precision medicine. Endocr Rev 2019;40:1500-20.

9 Flannick J, Johansson S, Njølstad PR. Common and rare forms of diabetes mellitus: towards a continuum of diabetes subtypes. Nat Rev Endocrinol 2016;12:394-406.

10 Hattersley AT, Patel KA. Precision diabetes: learning from monogenic diabetes. Diabetologia 2017;60:769-77.

11 Yang Y, Chan L. Monogenic diabetes: what it teaches us on the common forms of type 1 and type 2 diabetes. Endocr Rev 2016;37:190-222.

12 Weir GC. Glucolipotoxicity, $\beta$-cells, and diabetes: the emperor has no clothes. Diabetes 2020;69:273-8.

13 Balasubramanyam A, Garza G, Rodriguez L, et al. Accuracy and predictive value of classification schemes for ketosis-prone diabetes. Diabetes Care 2006;29:2575-9.

14 Patel SG, Hsu JW, Jahoor F, et al. Pathogenesis of $A^{-} \beta^{+}$ketosisprone diabetes. Diabetes 2013;62:912-22.

15 Mulukutla SN, Hsu JW, Gaba R, et al. Arginine Metabolism Is Altered in Adults with $A^{-} \beta^{+}$Ketosis-Prone Diabetes. J Nutr 2018;148:185-93.

16 Brooks-Worrell BM, Iyer D, Coraza I, et al. Islet-specific T-cell responses and proinflammatory monocytes define subtypes of autoantibody-negative ketosis-prone diabetes. Diabetes Care 2013;36:4098-103.

17 Fagot-Campagna A, Narayan KM, Imperatore G. Type 2 diabetes in children. BMJ 2001;322:377-8.

18 Mayer-Davis EJ, Lawrence JM, Dabelea D, et al. Incidence trends of type 1 and type 2 diabetes among Youths, 2002-2012. N Engl J Med 2017;376:1419-29.

19 Dabelea D, Mayer-Davis EJ, Saydah S, et al. Prevalence of type 1 and type 2 diabetes among children and adolescents from 2001 to 2009. JAMA 2014;311:1778-86.

20 Temple KA, Tjaden AH, Atkinson KM, et al. Association of habitual daily physical activity with glucose tolerance and $\beta$-cell function in adults with impaired glucose tolerance or recently diagnosed type 
2 diabetes from the restoring insulin secretion (rise) study. Diabetes Care 2019;42:1521-9.

21 Magliano DJ, Sacre JW, Harding JL, et al. Young-onset type 2 diabetes mellitus - implications for morbidity and mortality. Nat Rev Endocrinol 2020;16:321-31.

22 Matschinsky FM, Wilson DF. The central role of glucokinase in glucose homeostasis: a perspective 50 years after demonstrating the presence of the enzyme in islets of Langerhans. Front Physiol 2019;10:148.

23 De Backer I, Hussain SS, Bloom SR, et al. Insights into the role of neuronal glucokinase. Am J Physiol Endocrinol Metab 2016;311:E42-55.

24 Garrahy A, Mijares Zamuner MB, Byrne MM. An evolving spectrum of diabetes in a woman with GCK-MODY. Endocrinol Diabetes Metab Case Rep 2019;2019:EDM180145.
25 Maltoni G, Zucchini S, Scipione M, et al. Onset of type 1 diabetes mellitus in two patients with maturity onset diabetes of the young. Pediatr Diabetes 2012;13:208-12.

26 Maltoni G, Zucchini S, Martini AL, et al. Clinical heterogeneity in the same generation of siblings with GCK/MODY 2. Diabetes Res Clin Pract 2015;107:e1-3.

27 Fendler W, Małachowska B, Baranowska-Jazwiecka A, et al. Population-based estimates for double diabetes amongst people with glucokinase monogenic diabetes, GCK-MODY. Diabet Med 2014;31:881-3.

28 Standl E, Schnell O. Treatment paradigm shifting implications of recent cardiovascular outcome trials: core insights on the brink of the 2020ies. Diabetes Res Clin Pract 2020;161:108054. 